\section{PROFESSOR KOCH'S} \section{REMEDY FOR TUBERCULOSIS.}

\section{PROFESSOR KOCH'S TREATMENT OF TUBERCULOSIS.}

By C. THEODORE WILLIAMS, M.D., F.R.C.P., Senior Physician to the Hospital for Consumption and Diseases of the Chest, Brompton.

I VANTURE on a few notes gathered during my visits to the various clinics in Berlin, my principal object having been to determine the actual value of Koch's injection in the treatment of pulmonary phthisis.

It is a curious spectacle, and one by no means flattering to the votaries of science, to see the medical world of Berlin given up wholly to the worship of "Koch injection" and "reaction process," and all the usual pathological and clinical phenomena of tuberculosis set aside to make way for the one newly-found distinction of reaction or non-reaction after lymph injection.

The importance of the discovery can hardly be overrated, as it opens the door to a brilliant and apparently unlimited series of experiments in the treatment of all kinds of disease, acute and chronic; and when we look at the results of these injections in lupus, and watch the steps by which a terribly disfiguring eruption swells up, forms crusts which peel off and leave a healthy granulating tissue, we cannot withhold our astonishment and admiration, and we feel thankful for the relief to suffering humanity.

The same may be said of the effect of the injection on strumous joints and bone disease. The changes in the children in Professor von Bergmann's and Dr. Levy's clinics impressed me greatly, the little fellows who had been crippled for months using their hip and knee joints quite freely. But I will leave it to surgeons to explain the exact pathology of these changes.

I visited nearly all the clinics containing cases of phthisis, and examined about 100 in whom the disease dated from monthe to years, and whose lungs showed great diversity in the extent of the lesions present. There is no lack of opportunity of studying phthisis in the Berlin hospitals at present, for the city is fast becoming the receptacle of the phthisis of Germany, and even of some neighbouring countries, to the exclusion of other diserses. The Moabit Städtliches Hospital of 700 beds already contains a large proportion of consumptives, some of whom are under the personal observation of Professor Koch. The most striking effects of the injection are in laryngeal phthisis, where, with the reaction, swelling of the mucous membrane, and separation of greyish sloughs are visible under the laryngoscope, and, according to Professor Krause, both exfoliation and reabsorption of the swelling take place. Improvement in laryngeal phthisis is common, but complete cure rare.

The great mass of the cases of phthisis are such as may be found in Brompton and in other chest hospitals - partly cases of tuberculisation, partly cavity cases, though the conditions of hospital life are in many respects different, and $I$ regret to say in most of the Berlin hospitals there is still room for improvement, and especially in the sanitation. The main proportion of the patients have been under treatment two to four weeks, except in a few of Professor Fraentzel's and Dr. Levy's original cases. All have been subjected to frequent injections, the quantity of the 1 per cent. solution of the Koch's lymph injected varying from 1 or 2 milligrammes up to, in time, 25 milligrammes ( $2 \frac{1}{2}$ centigrammes). In some of the cases, which I will again refer to, after longer treatment even a larger dose is used. The reaction comes on at periods varying from 4 to 12 hours, according to Professor Fwald, and is sometimes delayed as long as 24 hours, but when it has once appeared its subsequent rise and course are tolerably uniform. The chief symptoms in consumptive cases appears to be rapid rise of temperature (reaching $103^{\circ}, 104^{\circ}, 105^{\circ}$, and even $106^{\circ} \mathrm{F}$.), quickening of pulse and respiration, the latter being especially marked, occasionally vomiting, increased cough and expectoration, with inspiration of the latter, often aphonia from temporary laryngeal catarrh. In some cases a scarlatinal rash has appeared, and in others (though generally lupus cases) a papular eruption, as I witnessed in two patients. In a few the nervous system appears much affected, as one patient became almost melancholic, and another perfectly unconscious after injection. The whole of these symptoms pass off in a few hours, and the patient returns to his ordinary state till the next injection. This is repeated next day or in a day or two with increased dose, and continued till all reaction ceases, when the tubercular disease, as far as active tuberculosis is concerned, is held to be arrested.

Nevertheless cases occur which cease to react under strong injections but still present the physical signs of phthisis and whose sputum contains tubercle bacilli. The existence of a reaction after injection is said to prove unmistakably the presence of tuberculosis, and Professor Koch informed methat if a patient, after successive injections, reached the centigramme dose without reaction he could be held free from tuberculosis. This may be so. But I examined in one of the clinics a middle-aged man, with a wellmarked cavity in the upper lobe of the right lung of some standing, with marked fibrosis of the rest of the lung and with some necrosis of the sternum, the supervention of which had relieved the cough, expectoration, and other lung symptoms. The sputum contained no tubercle bacilli. This patient gave no reaction after strong injections, but I should be sorry to affirm that he was not tubercular, the relief of one set of organs by the discharge from another system of tissues pointing very strongly to this conclusion. As an example of the extent to which the reaction test is pressed I give the following

A young man, with a history of cough and expectoration, was injected with a moderate dose. He had no physical signs or tubercle bacilli in' the sputum. No reaction following the injection was repeated after a few days' interval. Still no reaction. A third and somewhat stronger injection was followed, however, by a decided reaction, the temperature reached $102.2^{\circ}$ F., crepitation sounds were audible at one apex and tubercle bacilli detected in the sputum. This case was shown to me as a proof of the value of the injection as a means of diagnosis, but if the lymph is, as is generally believed, some form of a cultivation of the tubercle bacillus from which the bacilli are removed, there might be other ways of explaining these symptoms, which were, to say the least, very important.

The influence of injections on the tubercle bacilli in the sputum, was, as far as I could gather from the records, not very marked.

I had the advantage of being present at two post-mortem examinations on cases dying of phthisis in the Charité Hospital, which had been submitted to the treatment, and had received several injections. The necropsies were conducted in the most complete manner by Professor Virchow's able assistants, and showed in one case cavities of considerable size, and in the other a cavity at one apex, pneumonia at the base, with a large eruption of recently formed tubercle. In neither case was there any sign of cicatrisation or fibrosis, nor of more necrosed masses than are usually to be found in similar cases.

But to return to the living cases: The great portion of consumptives under the treatment appear to lose weight rather than gain, presumably on account of the fever reaction; the cough and expectoration seem lessened, but no solid improvement appears to be gained; this, however, only applies to the patients who have been under the treatment two or three weeks, which is the case of the majority.

A few old cases from Professor Fraentzel's clinic, and some which have been in Dr. Levy's, and are now in the Moabit Städtliches Krankenhaus give better results. These had all been between two and three months under treatment, and had had from thirty to forty-six injections, the quantities being gradually increased from 1 milligramme to a decigramme, which they stood without reaction. One of Professor Fraentzel's best cases was man, aged 26, who had consolidation of both apices with marked flattening on both sides. He had been injected forty-six times, and now gave no reaction even with a decigramme, which was still injected once in eight days. He had gained $10 \mathrm{lbs}$. , his cough and expectoration were moderate, and the tubercle bacilli in his sputum had diminished, though not quite disappeared.

Another good case was a man, aged 22, with a well marked contracting cavity in the left lung, and great retraction of the side, with signs of active disease at the apex of the right lung still present. He had been under treatment since Ostober 4th, and in these two months had received twenty-five injections, and now gave no reaction after a decigramme dose. Cough and expectoration were still present, and the signs at the right apex by no means quiescent. I was unable to ascertain whether the bacilli in the sputum had disappeared.

The six favourable cases I examined at the Moabit had been 
under treatment for three months, and had advanced from 1 milligramme to 1 decigramme injections, until all reaction ceased.

There were four males and all had improved, though not in weight, which is rarely gained under this treatment. All were examples of consolidation of one or both apices-as far as a hasty examination showed-and, in most, cough and expectoration were still present, and a few bacilli were detected in the sputum. The two females had improved rather more, and now presented only slight physical signs with moderate cough.

The above eight cases, with a few in Professor Ewald's clinic, were all I could collect, though I doubt not there are many more, as examples of genuine improvement under the Koch treatment, and this out of about one hundred examined by me. The improvement, though striking, is not more than is met with in the wards of the Brompton and other consumption hospitals under the ordinary conditions of diet and treatment. They would not for an instant compare with the results obtained at the high altitude sanitoria, such as Davos, St. Moritz, or Colorado, where the restoration to health is often complete, and no physical signs or tubercle bacilli remain.

My impression, however, is that the Koch treatment is worthy of a careful and prolonged trial in, when possible, as Professor Koch himself advises, proper sanatoria, with the addition of pure air and good food and careful nursing.

We owe much to Professor Koch, and it is only due to the great services which he has rendered to medicine that his treatment of phthisis should have a fair, full, and impartial trial; and this will be easier and more willingly undertaken when he has imparted to all scientific workers the complete details for preparing the lymph.

I cannot close this short and hurried communication without expressing my admiration of the liberality and courtesy of the Berlin professors and of the hospital staffs towards foreign medical men, who are welcomed in all the clinics, and are shown the patients, the wards, and the treatment without let or hindrance; and specially would I record my sense of obligation to Professors Gerhardt, Leyden, Senator, and E wald, for facilities afforded to me personally, as also to my friends Professor Virchow and Professor Liebreich for their unvarying kindness and valuable help during my stay in Berlin.

\section{CASES AT PADDINGTON GREEN ChILDREN'S hOSPITAL.}

\section{Second Report.}

THF cases at this hospital injected by Mr. Watson Cheyne have all undergone further treatment during the past week, and many of them areshowing distinct signs of improvement. Short descriptions of the twelve cases under treatment were published at page 1382 of the British Mrdical Journal of last week. We now continue the reports, and ar 3 indebted to Dr. Guthrie, the registrar of the Hospital, for the use of his notes of the cases, which are brought down to December 17th.

CASE I.-W. P., this patient has received four injections, the dose on the last occasion being 3 milligrammes. Resction occurred after each injection. During the height of the reaction after the third injection the urine contained one-tenth of albumen, and was loaded with urates. The albumen has since disappeared. There is no alteration in the abdomen.

CASR II.-J. F., as no reaction followed the first injection, this patient was sent home.

CAss III,-F. C., this girl has since December 10th received 3 injections of $1 \frac{1}{2}$ milligramme on December 11th, 13th and 15th, after which the temperature during the periods of reaction rose to $105^{\circ}, 1036^{\circ}$, and $101 \cdot 2^{\circ}$ respectively. December 17 th she opens the right eye; the elbow is much smaller, especially above the olecranon, and the threatened suppuration over the internal condyle, which fluctuated when the child was admitted, has now quite disappeared.

C $\triangle 8 R$ IV.-E. P., the reaction caused by the first injection on December 9th did not end until the evening of December 11th. During the 12th the temperature remained at about $99^{\circ}$. On December 13th, at 10.20 A.M. 2 milligrammes were again injected. The temperature began to rise at noon, and at 5 P.M. was $105.2^{\circ}$; at $8 \mathrm{pm}$. it had fallen to $1026^{\circ}$; on the 14 th at 9 A.M. was $996^{\circ}$, and has not since risen above $100^{\circ}$. The symptoms of reaction were severe each time, the pulse being $160^{\circ}$, and the respiration 66 , for five or six hours. As bronchitic sounds in both lungs were audible, no injection was made on December 15th to December 17th. The cervical glands are much smaller, the forearm is less swollen, and the amount of pus running from the sinus connected with the radius is also lessened.

CASR V.-E. C. during the week has received three fresh injections, two of 2 milligrammes and one of 3 milligrammes. The temperature during the reactions rose to $102.0^{\circ}, 104.4^{\circ}$, and $104.2^{\circ}$ respectively. The mass of enlarged glands in the right iliac fossa is much smaller. The scar over the fibula has never exhibited any reaction, and the sinus in the lumbar region remains unaltered, discharging as it did when the child was admitted.

CASE VI.-C. N. This patient has now been injected four times. The dose on the last occasion was 2 milligrammes. Reaction occurred after each injection. On December 17th the sinus, which was last week covered with yellowish tubercular tissue, was covered with healthy granulations, and was discharging thin serous fluid freely.

CASR VII. - In this child, who has now received four injections, each followed by reaction, the sinuses are now discharging thick yellow pus very freely. Six pustules have appeared at different parts of the skin of the back and abdomen, and, after discharging, have healed. There has also been a discrete papular rash over the chest and abdomen. The largest dose given was 2 milligrammes.

CASR VIrI.-L. B. during the week has been injected three times, twice with 5 and once with 4 milligrammes. The temperature reached $102.0^{\circ}, 103.8^{\circ}$, and $102.0^{\circ}$ respectively during the reactions. The glands have become much smaller. A curious point in this case was the fact that the upper lip and nose became swollen during the first two or three reactions, and that, upon examination, the lip was found to be cracked upon the inner surface. On December 17th this child was slightly jaundiced.

CASR IX.-P. S. was injected three times during the week, each time with 2 milligrammes, and the temperature rose to $102.0^{\circ}$, $105.2^{\circ}$, and $102.4^{\circ}$ during the various reactions. On December 17th the finger was much smaller; the redness diminished; the skin was wrinkled, and there was no pain nor tenderness.

CAsE X.-H. R. This boy was again injected with 4 milligrammes on December 11th. As no reaction ensued he was dismissed.

CASR Xr.-E.R. was injected three times during the week with 2,3 , and 4 milligrammes respectively. The reaction was slight after each operation. The temperature rose to $101.2^{\circ}, 101.0^{\circ}$, and $101.2^{\circ}$ during the reactions. The condition of the lungs appeared to be unchanged since the patient's admission.

CASE XIr.-E. M. was injected twice during the week with 1 and 2 milligrammes respectively. After the first the temperature rose to $101.2^{\circ}$; after the second to $104.0^{\circ}$. After each operation the skin around the point of puncture became red, painful, and swollen, but the inflammation subsided without any appearance of suppuration. The lung symptoms remain the same as when the child entered the hospital.

\section{FURTHER REPORT ON CASES AT THE HOSPITAL FOR} DISEASES OF THE CHEST, VICTORIA PARK.

THr following are notes of Dr. Heron's cases taken during the past week.

Casr I. Phthisis.-G. M., aged 23. After the ninth injection, December 10th, the temperature was somewhat depressed, and never touched the normal for twenty-four hours afterwards. Tenth injection, December 11th, 10 milligrammes; no reaction. Eleventh injection, December $12 \mathrm{th}, 12$ milligrammes; no reaction. Twelfth injection, December 13th, 12 milligrammes; no reaction. Thirteenth injection, December 14th, 13 milligrammes; slight reaction, without symptoms, except that six hours later the temperature went down to $97^{\circ}$. Fourteenth injection, December 15th, 14 milligrammes; no reaction. Fifteenth injection, December 16 th, 15 milligrammes; temperature went down to $96.8^{\circ}$ twenty-four hours afterwards, but no symptoms. Sixteenth injection, December 17th, 17 milligrammes. The patient said that he was feeling well; the cough had almost ceased. Physical signs: December 17th, dulness unaltered, right lung almost free from ráles, except a fow after coughing. Left lung, ráles present all down the front, but less numerous. Posteriorly: Bronchial breathing in the left supraspinous fossa, with moist clicks and a few râles in the lower part of the lung. The patient's weight has not altered since the commencement of the treatment.

CASR II. Phthisis. - A. D., aged 40. No reaction followed the ninth injection, December 10th. Tenth injection, 10 milligrammes, December 11th. Eleventh injection, 10 milligrammes, December 
12th. Twelfth injection, 11 milligrammes, December 13th. Thirteenth injection, 12 milligrammes, December 14th. Fourteenth injection, 13 milligrammes, December 15th. Fifteenth injection, 14 milligrammes, December 16th. Sixteenth injection, 16 milligrammes, December 17 th. The temperature had af uer each injection at first gradually fallen, and then risen to its highest point about twenty-one hours after the injection, so that twentyone hours after the twelfth injection it rose to $99.2^{\circ}$, after the fourteenth injection to $100.2^{\circ}$; no symptoms. The patient considers that he is improving every day ; the expectoration is certainly much less. On December 16th the following note was taken:- "Left lung clear; right lung râles over anterior apex still numerous; percussion note not clear; posteriorly, numerous rales in right supraspinous fossa, and a few can be heard down to the base."

CA8E IIr. Phthisis.-B. W., aged 22, after the sixth injection on December 8th, as the temperature was depressed, Dr. Heron discontinued the injection for some days to watch the temperature, and during this time it varied only slightly from the normal. Seventh injection, 5 milligrammes, December 14th; twenty-one hours later the temperature rose to $99^{\circ}$, and the patient complained of slight headache. Eighth injection, 5 milligrammes, December 16th. Ninth injection, 7 milligrammes, December 17th no reaction since December 15t3. The expectoration is less, and the patient says that he feels "all right."

Cısz IV. Lupus.-L. F., aged 21. Fourth injection, 6 milligrammes, December 15th. In six hours and a quarter the temperature rose to $104.2^{\circ}$, in twelve hours and a half it was $102.8^{\circ}$, and in thirty-four hours it had dropped to $97^{\circ}$. Her symptoms during the reaction were eimilar to but less marked than after previous injections. Her pulse and respiration ratio underwent a remarkable alteration. During the height of the reaction, for six hours she was breathing very rapidly, about 90 to the minute, her pulse rate being 98. Both pulse and respiration varied slightly from these numbers. During this time there were no symptoms t) cause anxiety, no stupor or marked dyspnos, and the patient could talk quite rationally and collectedly to the nurse and resident medical officer. The local reaction was less marked than on previous occasions, and subsided in about thirty hours.

CAsR v. Lupus.-E. R., aged 27. Third injection 1 centigramme, December 15tb. Temperature rose to $104^{\circ}$ in six hours, $104.4^{\circ}$ in ten hours and a half, and remained at $104.4^{\circ}$ till twelve hours after the injection, when it dropped gradually and reached the normal in forty-two hours, and to $97^{\circ}$ in forty-four hours. During the reaction she had headache and slight shivering, much thirst, but no vomiting; locally the parts were swollen, but forty-eight hours after the injection were only very slightly redder than just before the injection.

CAsk VI. Phthisis.-H. D., aged 14. No injection was given for five days to watch the temperature, which had been depressed after the preceding injection. It remained not far from normal, but showed slight variations all below the normal. Eleventh injection, 5 milligrammes, December 14th; no reaction. Twelfth injection, 7 milligrammes, December 15th, after which there was a slight reaction, and the patient felt hot, weak, and restless, and had nausea and headache. Thirteenth injection, 8 milligrammes, December 16th. Temperature at first fell slightly, and then rose in twenty-four hours to $100^{\circ}$, at which time she again complained of feeling feverish, sick, and thirsty, with headache. There was no vomiting: her breathing was quite quiet, though rapid, 60 , and pulse 100. She was menstruating. Physical signs: dulness unaltered; rales can be heard at the spine of the left scapula, and, after coughing, at the left apex.

CAsm VIr. Phthisis.-H. B., aged 28. Thirteenth injection, 8 milligrammes, December 16th. Fourteenth injection, 10 milligrammes, December 17th. Had slight general sweating shortly after each injection, but no other reaction. The patient is doing very well, and only a very few bacilli can be found in very scanty sputum. Cough is very slight.

CASE vIII. Ancemia.-A. B., aged 18. Dr. Heron in this case, on December 13th, gave an injection (the eighth) of distilled water, to ascertain whether the act of injection was able to produce a reaction, but the result was negative. Ninth injection, 5 milligrammes, December 14th. No reaction until the following day, when her temperature reached $100.6^{\circ}$, twenty-four hours after, and then he geve her the tenth injection, 7 milligrammes, December 15th. The temperature remained close to, or just above, $100.0^{\circ}$ for twenty-nine hours, and then dropped, in thirty-six hours, to $98^{\circ}$. She had pain, but no swelling of her right knee.
Otherwise says skin quite well, and no signs of tubercle are present. Eleventh injection, 7 milligrammes, December 17 th.

CAsR IX.-E. F., aged 57. Third injection, 5 milligrammes, December 15th, followed by a slight reaction. On December 17th the affected parts were much redder than before the infection.

\section{KING'S COLLEGE HOSPITAL.}

Mr. Watson Chryne's Cashs: Third Rhport.

Thrar is very little new to report concerning the cases under treatment at King's College Hospital. The very interesting case of supposed tubercle of the iris has been injected for the fifth time (2 milligrammes on December 12th), but it can hardly be said that much alteration has taken place in the eye, except, perhaps, that the tubercle has grown larger. A more satisfactory account can be given of the cases of lupus. After six injections the woman, with extensive lupus of the face (Cake I, M. C.) i decidedly improved. The hard margin has disappeared, and tubercles can no longer be discerned. There is still general reaction after the injection, both in this and the other cases, but it seems to be becoming less; the local reaction has almost ceased in many instances. In the case of the youth with lupus patches on the thigh and in the axilla, the improvement is very marked in the thigb, but the patch in the axilla is still surrounded by a ring of tubercles. In the first case in which injection was done (N. L., Case Xv) only two have been given She has, however, recovered in a degree from the profound disturbance which they caused, and a sinus over the metacarpal bone, which had discharged for four years, is now healed. This patient, like several others, seems to have had a slight attack of jaundice after the injection (1 milligramme on December 1st). With regard to the other cases, we can only say that they have reacted both locally and generally in the now well-known way, but that in other respects they afford no results which at present call for notice. It may, however, be of interest if we add that a case of anæsthetic leprosy is now included in the cases shown. It is that of a woman, aged 54 (Case $\times x \mathrm{~V}$ ), who has nursed cases of leprosy in Calcutta. She first noticed the disease ten years ago, when it began with maculæ followed by the usual trophic changes in the fingers and toes. A dose of 10 milligrammes on December 10th was followed by a temperature of $104.6^{\circ} \mathrm{F}$., and the appearance of a rash upon the chest and abdomen. She stated this was the same as that which she had when the disease began. A large bulla also appeared on the left big toe. The injection (10 milligrammes) was repeated on December 14th, and was followed by a temperature of $103^{\circ} \mathrm{F}$.

[Subsaquent reports on these cases will be published at longer intervals.]

THE ROYAL HOSPITAL FOR CHILDREN AND WOMEN. Dr. SePtimus SundRRLAND has injected during the past week, in the hospital, the following cases, two of which are under the care of his colleague, Mr. Jacobson, who kindly gave his permission for the treatment:-1. Lupus of nose, which had been scraped several times previously. 2. Early phthisis of left apex. 3. Tubercular glands of neck. 4. Adenoids of pharynx. 5. Old excision of hip with sinuses. 6. Hip-joint disease. In each case small doses were injected at the first inoculations. Each case reacted. Careful observations are being made, and notes taken, with the assistance of Dr. Enoch Moss and Dr. Wheaton, and it is proposed to publish the cases more in detail later on, with several others.

\section{NEWCASTLE.}

OUR Newcastle Correspondent writes :-Dr. J. D. Rutherford, of Newcastle, having returned from Berlin bringing with him a supply of Koch's lymph, and having generously placed a portion of it at the disposal of the staff of the Royal Infirmary, a series of four experimental injections were made in the presence of a numerous body of medical practitioners and students on Tuesday, December 8th, 1890. Dr. Philipson, in an introductory address, explained the rationale of the process. The first case was one of lupus of the right side of the face and arm in a boy, aged 10 years. The disease was of nine years' duration. One milligramme of the fluid was injected in the interscapular region, and the patient placed in bed. The injection was followed in about four hours by a steady rise in temperature to $103.8^{\circ}$, at which point it remained 
for some time, and then gradually fell to $100^{\circ}$. The lupus patches became injected, red, and swollen.

On December l2th he was again injected, the same dose being given, and was followed in the ev sning by characteristic reaction. The lupus patches show signs of improvement, and the result in this case, so far, is very satisfactory.

The second case was considered by Dr. Drummond as rather advanced pulmonary tuberculosis of the left lung. In this case there was tubercular family history, and the presence of the bacillus had been demonstrated in the sputum. One milligramme of the fluid was injected, but was nol followed by any reaction as anticipated. The following morning a second injection was given, rather stronger than the first, without reaction. He was again injected with two milligrammes next morning, and this was followed by slight reaction. The presence of the bacillus has been $\theta$ gain demonstrated in the sputum, and this case would seem to detract from the diagnostic value of.the ly mph.

The third case was one of tubercular disease of the elbow-joint in a nurse of the institution, under the care of Dr. Hume. The injection in this case was follow ed by very interesting phenomena. The temperature rose to $103^{\circ}$; the surface temperature of the diseased joints rose to between three and fourdegrees higher than on the sound side. An incision made by Dr. Hume some months previously remained normal, whilst the scar of an old sinus was injected and swollen.

The fourth case was one of tubercular glands in the neck under the care of Mr. Williamson. Characteristic reaction followed, temperature rose to $103^{\circ}$, and the neck was swollen and tender over the site of the glands.

At the meeting of the Northumberland and Durham Medical Society, Dr. Rutherford inj cted a case of Dr. Oliver's. The results of the injection with complete observations will no doubt be published.

EXPERIENCE AT GLASGOW.

So far as the treatment of patients with Koch's fluid at the Royal Western and Victoria Infirmaries at Glasgow has progressed, the results do not differ from the average of those obtained elsewhere. The experience has been far too short to permit of any opinion whatever being expressed as regards the therapeutic effects, even in the cases of lupus; but short as the experience has been, it has yet been sufficient to testify to the diagnostic value of the treatment. In certain cases-presumed phthisical-where yet no bacilli were found, the absence of reaction, after even a maximum dose, has confirmed the doubt as to their tubercular character. Some of the most marked effects have been obtained in tubercular diseases of the joints. In one of Dr. Napier's cases, a case of phthisis, in which, under the usual treatment, marked improvement had gradually taken place, the injection revealed hitherto unsuspected disease in the other lung. With the exception of two or three doubtful cases already noted, the nsual charactéristic' reaction had been obtained. Thus, in one case, following an injection of 0.001 gramme, the temperature rose to $102.2^{\circ}$; two days later a dose double the strength was followed by an elevation of temperature equal to $1024^{\circ}$; a third dose of 0.004 gramme, after another interval of two days. was followed by a rise to $1026^{\circ}$; and in other two days a dose of 0.006 gramme raised the temperature in nine hours to $104^{\circ}$, but it fell in twelve hours to $100^{\circ}$. Another Royal Infirmary case which showed no reaction to dose $s$ of $0.001,0003,0.006$ gramme on successive days, reacted to a dose of 0.008 gramme, the temperature rising to $100.8^{\circ}$; and two days thereafter an injection of 0.01 gramme raised the temperature in about five hours to $100.8^{\circ}$, but it had returned to normal in eighteen hours. The cases of lupus have illustrated in a marked way the characteristic reactions by the effects on the ulcerated patches as well as constitutionally. One of the cases treated at the Victoria Infirmary-a case of lupus of the faco-showed on chest, abdomen; and limbs an extensive rash, resembling scarlet fever, as a reeult of injection.' One of the Royal Infirmary cases of lupus showed a similar eruption following an injection of 0002 gramme, the temperature rising to $104^{\circ}$. The progress of the cases is being followed with great interest.

\section{DUBLIN.}

OUR Dublin Correspondent writes: A large number of cases are under the Koch treatment in most of the Dublin hospitals at present. They present the usual features in their course, which are now so well known, and they are watched with great interest by the gentlemen having charge of them. The lupus cases are of special importance, because their progress can be clearly observed, but the treatment is being also largely tried on all other forms of tuberculosis. Dr. McKee has been asked by the Council of the College of Surgeons to deliver a lecture on the subject on Thursday, December 18th.

NOTES FROM BERLIN.

[FROM OUR SPECIAL CORRESPONDENT.]

Professor Gerhardt's opinion.-Dr. Cornet's Sanatorium.-Precautrons taken by the Berlin Board of Health.-Alleged Cure in two Cases.

ON Saturday, December 13th, Professor Gerhardt again gave an address on his experience with Koch's remedy, and announces that from this week forward no further exhibition of cases for foreign physicians will be held. Professor Gerhardt has treated 59 patients with 380 injections in all, giving 2 milligrammes as a first dose usually, though in special cases this was reduced to 1 milligramme. Two patients have been treated with 12 injections, one with 13 ; the highest dose renched was 1 decigramme. Amongst the cases was one with tuberculous affection of the larynx. Only 1 milligramme was given at first, but in spite of the smallness of the dose, a swelling supervened, narrowing the glottis to a sixth of its former size, and, therefore, only four injections were given in all. The treatment was stopped on December 9 th. In spite of these precautions, such an alarming attack of dyspnœe supervened during the night of December $13 \mathrm{th}$, that tracheotomy had to be performed on the already unconscious patient. In 24 cases the body weight remained unchanged ; in 14 cases it decreased, one patient losing 4 kilogrammes; 10 cases showed an increase of weight. In most cases the general condition was lowered, but in many cases the night sweats ceased. A most important feature of the remedy was its action on the respiration. The respiration, which in some cases remained uninfluenced, was in others considerably accelerated, sometimes even to an extent usually only observed in severe inflammation of the lunge. Three patients died, two of whom were in an advanced stage of the disease, whilst the death of the third was due to another cause; two patients left the hospital, as they themselves considered, materially improved. Of 24 cases, 11 felt very well, 6 felt wretched, the rest felt tolerably comfortable. In some cases the treatment had to be stopped. Gerhardt added that Koch's warning only to use the remedy in the initial stage could not be too earnestly borne in mind. His impression was that the chances were better in cases of tuberculosis of the larynx than in cases of phthisis pulmonum. Where there was continuous fever the prognosis was unfavourable, and it was a bad sign if the treatment produced continuous fever where there was none previously. Gerhardt thinks the diagnostic value of the remedy beyond doubt.

Dr. Cornet is about to cpen a sauatorium of 100 beds for treatment by Koch's remedy at Charlottenburg, near Berlin. The pavilion hospital, which is being erected for Koch in the Charite grounds, is progressing briskly. in epite of the extreme cold, which renders building work very difficult.

As a measure of precaution against the dangers to which Berlin is just now exposed through the influx of tuberculous visitors, the police authorities - acting in concert with the municipalityhave issued an order by which all cases of tuberculosis (of whatever kind) occurring in hotels, boarding houees, furnished lodgings, private sanatoria, or other establishments of a similar description. are to be classed amongst the infectious diseases; the head's of such establishments are under the obligation to take the usual precautions as to disinfection. Further, medical practitioners who have cases of tuberculosis in any such establishments under treatment are required to give notice to the Board of Health within twenty-four hours.

Dr. Paul Guttmann, who has charge of sixty-six consumptive patients treated with Koch's remedy, had the satisfaction of presenting two cases, which he considers completely cured, to the members of the Hufeland Gesellschaft. These were two young girls on whom the treatment had been tried at the initial stage of consumption. The dose had been increased to 5 centigrammes, and Dr. Güttmann added that he was now giving a young man under his care doses of 10 centigrammes. 
LEPROSY AND PROFESSOR KOCH'S TREATMENT.

Srr,-From the pathological analogies of tuberculous and leprous tissue, and from the similarity of the respective bacilli in certain of their relations, it occurred to me that like results might be expected by the use of Dr. Koch's remedy in cases of leprosy. I accordingly wrote to the professor on the subject some weeks ago, and he has now been kind enough to send me a supply of the fluid, particularly for the use of leper patients. I shall be glad to hear from any medical man who may have a case of the kind at present in England, and willing to be treated. A definite effect has, I believe, already been obtained in Vienna by Professor Kaposi in a leper, and I understand that the remedy is now being tried, by Dr. Koch's advice, for leprosy in Germany.-I am, etc.,

Phin. S. Abraham, M.D., Medical Secretary, Cavendish Square, W. National Leprosy Fund.

SIR,-In Koch's treatment a substance is inoculated which is detrimental to the tubercular tissues. The same process is at work in a similar but slower manner in many cases of tuberculosis, that is, a tendency on the part of the individual to immunity from general tubercular affection by a process of attenuation from a local one. It is generally acknowledged that in a family with strong tubercular tendencies those members of the family who in early life have been the subjects of caseating lymphatic glands, are far less liable to succumb later on from phthisis than are those members of the same family who have not had tuberculous glands at some period.

Again, if a patient be the subject of one marked expression of scrofula, he very seldom develops another strumous disease at the same time. Some writers have spoken of this as an antagonism between the various tubercular affections in the sam $\theta$ individual. One observer states that of children the offspring of parents with a tubercular taint, so me become decidedly scrofulous, others remain free from any actual disease and are simply delicate. The former are less liable to phthisis than are other individulls, while the latter would be especially prone to become consumptive. In other words, the former subjects have been through the slow process of protective inoculation of some substance produced by the tubercular process at the time this was active, and which body is itself a preventive to the future development of the disease. This substance, whose presence is antagonistic to the disease, gives immunity to the individual for some future period, and if at any time artificially introduced in sufficient quantities arrests and destroys the tubercular processes actually in existence in the tissues.

In animals afflicted with tuberculosis, there is an enormous amount of tubercular material being constantly removed from the system. In man in cases of pulmonary phthisis this is chiefly attained through the respiratory channels, in the form of expectoration. In the case of various strumous affections which have broken down, large quantities of tubercular material are discharged, usually externally. In birds the same or even a proportionally much greater amount of dead matter is removed from the animal through the intestinal tract. Tuberculosis both in man and lower animals is probably in nearly all cases, primarily local affection. The disease is at first a local one, and in the early stages only affects the general system by the slow absorption of the poisoned bodies formed by the tubercular elements. Probably aslong as the deposits are isolated by the dense capsule of fibrous tissue, there is a possibility of a cure being affected, but in time the essential tuberculous elements find their way into the circulatory system and the disease becomes a general one.

Whatever the exact nature of Koch's inoculating fluid, its action appears to be the rapid destruction of the tuberculous granuloma en masse. There being no regular circulation through the deposits, the peripheral regions, that is, those consisting of granulation tissues, must be those which become affected by the injected substance; in other words it would appear that these are the essential elements of tuberculozis. The bacilli themselves according to Koch are not destroyed. The action of the lymph on the animal is thus merely an exaggeration of what normally occurs in every case of tuberculosis. The great problem yet to be solved in connection with the whole question is how to remove the diseased material thus freed from the surrounding tissues and from the body?

Harley Street, W.

Walter K. Sibley, M.B.Camb.

\section{BRITISH MEDICAL ASSOCIATION. SUBSCRIPTIONS FOR 1890.}

Subscriptions to the Association for 1890 became due on January 1 st; and notice is hereby given, in accordance with by-law 5, that Branch Secretaries' subscription-accounts close on October 31st, and all unpaid subscriptions must be forwarded, after that date, to the General Secretary, 429, Strand, London. Post Office Orders should be made payable at the West Central District Office, High Holborn.

\section{The Brítísh ftedícal Journal.}

$$
\text { SATORDAY, DECFMBER 20TH, } 1890 .
$$

\section{EDUCATION AND CULTURE.}

THE address given by the German Emperor at the opening meeting of the German Committee on School Reform was really a very remarkable sign of the times. Much of it was of special application to Germany, but the fundamental position would be equally true in this country. The teachers of langurges, he contended, had used their long supremacy less to form character and to make youths fitted to meet the needs of modern life, than to give them a philological acquaintance with certain dead languages. "Their principle is that the pupil must know as much as possible, whether it be of use in after-life or not, and if one tries to point out to these gentlemen that a young person must be prepared with some kind of practicality to face life and its problems, they answer that the province of the school lies not in that but in mental gymnastics. I believe that this standpoint will have to be abandoned." After giving some of his own experiences in the composition of Latin essays-experiences which might be paralleled by most of those who in this country have had to to write Latin verses-_"the Latin essay," he concluded, " must be abandoned, for it leaves too little time for the study of German."

Mutatis mutandis this is very much the thought which underlay Dr. Wade's Presidential Address to the British Medical Association at Birmingham this year. Is Latin, he asked, a necessity, an evil, or a superfluity for the medical student? Professor Huxley has long since made up his mind upon the subject, and has often expressed his opinion with no uncertain sound; and however little we may agree with him, we can at least admire the candour and determination with which he advances his views.

Let us for the moment dismiss all theories from our minds, and set ourselves to discover what it is that the medical student most requires to make him a successful practitioner of medicine, using the term in its widest sense. In what respect is his education to differ, say, from that of the lawyer, the clergyman, or any ordinary man of intelligence? Should it, indeed, differ at all before he enters a medical school and commences his technical studies? Running through the minds of most of those who have expressed their ideas on the point are two dominant ideas-science and practice. Give a man a good education, say those who hold the older view, and he will not fail to apply his mind to the various questions with which he is called upon to deal in his life's work. The more modern view as- 